\title{
Matrix Metalloproteinases-Modulating the Tumor Microenvironment
}

\author{
Marzenna Wiranowska ${ }^{1}$, Amyn M Rojiani ${ }^{2}$ and Mumtaz V Rojiani ${ }^{2,3^{*}}$ \\ ${ }^{1}$ Department of Pathology and Cell Biology, Morsani College of Medicine, University of South Florida, Tampa, Florida, USA \\ ${ }^{2}$ Departments of Pathology, Medical College of Georgia-Georgia Regents University, Augusta Georgia, USA \\ ${ }^{3}$ Department of Medicine, Medical College of Georgia-Georgia Regents University, Augusta Georgia, USA
}

*Corresponding author: Mumtaz V Rojiani, Departments of Pathology and Medicine, Medical College of Georgia, Georgia Regents University, Augusta GA 30912, USA, Tel: (706) 721-0295; E-mail: MRojiani@GRU.EDU

Received date: February 13, 2015; Accepted date: May 04, 2015; Published date: May 11, 2015

Copyright: (c) 2015 Wiranowska M, et al. This is an open-access article distributed under the terms of the Creative Commons Attribution License, which permits unrestricted use, distribution, and reproduction in any medium, provided the original author and source are credited.

\begin{abstract}
Observations on the collagenolytic activity of endopeptidases in tadpoles undergoing metamorphosis were the early steps in defining this family of matrix metalloproteinases (MMP). Extensive investigations into these enzymes in plants and animals have revealed the highly pleiotropic nature of these molecules, both in physiologic and pathologic conditions. The human MMP family is comprised of over 23 members, which are capable of degrading and processing almost all components of the extracellular matrix (ECM) such as proteins and proteoglycans including those of basement membrane. MMPs also can cleave a wide variety of non-matrix substrates such as cytokines, chemokines, growth factors and their receptors as well as adhesion molecules important in tumor microenvironment and at all stages of tumor progression.
\end{abstract}

Keywords: Matrix metalloproteinase; Tumor microenvironment; Extracellular matrix; Review

\section{Introduction}

Observations on the collagenolytic activity of endopeptidases in tadpoles undergoing metamorphosis were the early steps in defining this family of matrix metalloproteinases (MMP) [1]. Extensive investigations into these enzymes in plants and animals have revealed the highly pleiotropic nature of these molecules, both in physiologic and pathologic conditions. The human MMP family is comprised of over 23 members, which are capable of degrading and processing almost all components of the extracellular matrix (ECM) such as proteins and proteoglycans including those of basement membrane. MMPs also can cleave a wide variety of non-matrix substrates such as cytokines, chemokines, growth factors, and their receptors as well as adhesion molecules important in tumor microenvironment and at all stages of tumor progression [2-5].

MMPs are synthesized as zymogens and either secreted from the cell into ECM or anchored to the plasma membrane, or some are even found as intracellular proteins. Their expression is mainly regulated at the transcriptional level, but recent reports suggest that posttranscriptional events may play a role [6]. Most of MMPs contain four distinct functional domains such as: signal peptide, propeptide, catalytic domain, and hemopoexin-like domain [5]. They all share a highly conserved zinc binding site in their catalytic domain.

The classification of MMPs summarized below in Table 1 is based on their substrate specificity, domain organization and function $[5,7]$. MMPs that play an essential role in the tumor microenvironment can be found in each of these groups [8-10].

\section{MMPs: Cellular Sources and Role in Inflammation}

One of the hallmarks of cancer is inflammation. Various proinflammatory factors, including cytokines and MMPs are produced by the tumor as well as by the tumor surrounding stroma. The inflammatory cells of the stroma which contribute to the microenviroment of tumor include: mononuclear cells such as monocytes and macrophages; granulocytes such as neutrophils, eosinophils, and basophils/mast cells and $\mathrm{T}$ and $\mathrm{B}$ lymphocytes. Together, these cells can enhance turnover of ECM and tumor cell migration. Stromal cells such as tumor-infiltrating leukocytes including mononuclear cells (monocytes and macrophages), granulocytes (neutrophils, eosinophils, basophils/mast cells) and lymphocytes are known to be main producers of MMPs. A wide variety of MMPs can be produced by these cells including (MMP-1,2,3,7,9,10,12,13,14,19) capable of degrading ECM and inducing tumor angiogenesis. MMP-9 which is directly involved in angiogenesis is released mainly by macrophages at the tumor site. For example it was recently shown that glioma-associated microglial/ macrophage MMP-9 expression promotes glioma infiltration into the normal brain parenchyma [11]. It had previously been shown that macrophages, mast cells and peripheral mononuclear cells amplify neoplastic cell proliferation and angiogenesis which was mostly attributed to the release of MMP-9 by these cells [12].

The release of MMPs from granulocytes in general, is based upon demand. MMPs released by neutrophils are MMP- 8 and MMP- 9 with latter shown to be highly potent proangiogenic enzyme. Tumorinfiltrating neutrophils localize predominantly in the tumor interior, in contrast to monocytes/macrophages which are found at the tumor periphery or tumor/stroma border. Mast cells produce MMP-9 and MMP-2, and like basophils, are able to release the vasoactive agents from their granules.

Other important cells in the tumor stroma are fibroblasts, endothelial cells and perivascular pericytes, which can also express MMPs $[13,14]$. The cross-talk between tumor cells and normal stromal cells can trigger fibroblasts to express MMPs, e.g., MMP-9. Other known fibroblast-derived MMPs includes MMP-1, 7 and 14. In addition, activated endothelial cells of the capillary network overexpress several MMPs (MMP-1, 9, and 14) during sprouting and 
Page 2 of 7

formation of lumina-containing tubules, although these cells are relatively deficient in MMP expression when in a quiescent state. Perivascular cells such as pericytes and smooth muscle cells have also been implicated in tumor angiogenesis, and pericytes have been shown to express MMP-9. Interestingly and as would be expected, it is believed that upon maturation of newly formed blood vessels, the interaction between pericytes and endothelial cells can lead to the silencing of MMPs [14,15].

\begin{tabular}{|c|c|c|}
\hline Family & MMPs & Key characteristics \\
\hline Collagenases & MMP-1, -8 , and -13 & $\begin{array}{l}\text { These can cleave collagen and are able to process other } \\
\text { ECM molecules }\end{array}$ \\
\hline Gelatinases & MMP-2 and -9 & $\begin{array}{l}\text { Play an important role in the remodeling of collagenous } \\
\text { ECM, also targeting other ECM and non-ECM molecules }\end{array}$ \\
\hline Stormelysins & MMP-3, and -10 & $\begin{array}{l}\text { Process many ECM components as well as some growth } \\
\text { factors, cytokines and adhesion molecules, except for the } \\
\text { native collagen }\end{array}$ \\
\hline Stormelysin-like MMPs & MMP-11, and -12 & $\begin{array}{l}\text { MMP-11- induced in adipose tissue by cancer cells, and is } \\
\text { responsible for tumor progression through the degradation } \\
\text { of collage VI. }\end{array}$ \\
\hline Matrilysins & MMP-7, and -26 & $\begin{array}{l}\text { Play important roles in degradation and processing of } \\
E C M \text { and non-ECM proteins }\end{array}$ \\
\hline $\begin{array}{l}\text { Transmembrane MMPs } \\
\text { also known as MT1-, MT2-, MT3- and MT5-MMP } \\
\text { respectively }\end{array}$ & MMP-14, $-15,16$, and -24 & \multirow{2}{*}{$\begin{array}{l}\text { Located on the cell surface and control the local } \\
\text { environment of normal and tumor cells. Main activators of } \\
\text { proMMP-2 and are involved in blood vessel formation. } \\
\text { Also upregulated in tumors and in some cases associated } \\
\text { with poor prognosis of several types of cancer. }\end{array}$} \\
\hline $\begin{array}{l}\text { Glycosyl-phospatidyl-inositol (GPI)- type MMPs } \\
\text { also known as MT4- and MT-6-MMP }\end{array}$ & MMP-17, and -25 & \\
\hline MM-19-like MMPs & MMP-19 and -28 & $\begin{array}{l}\text { Produced by several carcinomas although their role is not } \\
\text { yet well defined. MMP } 28 \text { is believed to play a role in } \\
\text { several diseases of the central nervous system (CNS) } \\
\text { including multiple sclerosis. }\end{array}$ \\
\hline Other MMPs & MMP-18, -20 , and -23 & $\begin{array}{l}\text { MMP23 - produced by various normal tissues but their } \\
\text { precise roles have not yet been elucidated }\end{array}$ \\
\hline Disintegrin/Metalloproteinase & $\begin{array}{l}\text { ADAMs (a disintegrin and metalloproteinase) } \\
\text { and the ADAMTS (a disintegrin and } \\
\text { metalloproteinase with thrombospondin motif) }\end{array}$ & $\begin{array}{l}\text { An interaction between MMPs and ADAMTS was reported } \\
\text { with MT4-MMP contributing to activation of ADAMTS-4 }\end{array}$ \\
\hline
\end{tabular}

Table 1: The classification of MMPs.

The expression of MMPs is regulated by various inflammatory cytokines. For example, TNF-alpha secreted by macrophages in response to pro-inflammatory signals has stimulatory effect on MMPs produced by these cells. It was shown previously that a co-culture of tumor cells with macrophages resulted in enhanced MMP expression and invasiveness of tumor cells $[16,17]$. Recently, it was also reported that pro-inflammatory cytokines such as Interleukin (IL)-8 and -IL-17 enhance the activity of MMP-2 and MMP-9 which in turn increases cancer metastasis [18].

MMPs themselves can also regulate the inflammatory response [19]. For example, MMP-9 can enhance the activation of proinflammatory cytokines such as TNF, IL-1 beta, IL-6 and IL-8, but MMP-2 may dampen the inflammatory process [20]. On the other hand, some cytokines can have an inhibitory effect on the secretion of MMPs. For example, interferon (IFN) alpha/beta inhibited tumor cells secretion of active form of MMP-2 and chondroitin sulphate proteoglycan (CS), an ECM component, as well as tumor cell migration $[21,22]$.

These interactions involving many cell types producing a range of MMPs within the tumor and the bordering stroma, as well as interaction of MMPs with their stimulators, inhibitors and substrates become even more complex at the cellular level. Thus, depending on the cellular source, the activity of a single MMP could have either inhibitory or stimulatory effect on tumor growth.

\section{Targets and Substrates of MMP Action: Cellular or Extracellular}

Our understanding of MMP action has been greatly enhanced by the generation of mouse models. These have particularly facilitated the identification of many other in vivo substrates for MMPs, including many more non-ECM bioactive molecules. This includes growth factors receptors, adhesion molecules, cytokines, chemokines, angiogenic factors, apoptotic ligands, etc. [23,24].

\section{ECM substrates}

Proteolysis of the extracellular matrix leading to migration and invasion of tumor and endothelial cells is an important action mediated by; MMP-14, which has been recognized as one of the most potent modifiers of the extracellular tumor microenvironment [25-27]. In addition, MMP-14 participates in the angiogenic process in growing tumors $[15,25,28,29]$. Remodeling of the basement membrane 
Page 3 of 7

matrix and in particular the basement membrane of endothelial cells, is a critical initial step in the angiogenesis process. The basement membrane, rich in laminins and collagen IV, undergoes degradation and re-assembly [30], with MMP-2, 9 and 14 playing a role in remodeling of the basement membrane in vivo [31]. The expression of MMP-2 by lung carcinoma metastatic to the brain has been correlated with increased angiogenic profiles at the metastatic tumor-host interface [32], likely modulated by these same mechanisms.

\section{Non-ECM substrates}

Various pro-angiogenic factors or inhibitors of angiogenesis are released secondary to modification of ECM or cell surface by MMPs [33]. An example of non-ECM substrates are cell surface adhesion molecules, e.g., CD44. The transmembrane proteoglycan CD44, which is found at the leading edge of the invasive tumor [34] was shown to bind through its extracellular domain to several MMPs including MMP-2. As a result of this interaction, the MMPs were localized at the migrating front of the tumor, leading to proteolytic degradation and promoting cell mobility [35]. In addition, it was also found that binding of MMP-9 to CD44 promotes MMP activation [23].

\section{Impact of MMP on Tumor Microenvironment and Growth}

Tissue remodeling, an important MMP function, is a result of interactions with and modulation by a network of cytokines and growth factors. Recall that both the ECM and basement membrane serve as storage points for cytokines and growth factors bound to proteoglycans. Enzymatic degradation of the ECM therefore results in the release and diffusion of cytokines and growth factors as well as activation of ECM molecules important in tissue pathology. Additionally, MMPs act as sheddases or convertases, as they transform membrane-bound cytokines, cytokine receptors, and adhesion molecules, into their soluble forms [36,37]. The proteolytic action of MMPs affects basic cellular events such as cell proliferation, migration, adhesion, and also physiological processes related to ECM remodeling such as angiogenesis. In the tumor microenvironment, the proteolytic modification of many complex fibrillar proteins by MMPs facilitates protease-dependent tumor cell migration and tumor angiogenesis. Therefore, the upregulation of MMPs has been associated with many pathological processes including inflammation and cancer.

MMPs in vitro show overlapping affinities for different ECM and non-ECM substrates and many MMPs can degrade and process several different classes of ECM proteins, e.g., MMP-2 and MMP-9 can degrade collagens I, IV, V, VII and X, gelatin, elastin, fibronectin, and proteoglycans.

\section{Tumor cell proliferation and inhibition of apoptosis}

Tumor progression from its earliest phase i.e. the growth of tumor cells at the primary site involves MMP activity. MMPs control cell division and proliferation through regulation of growth factor availability and activation or inactivation of growth factor receptors, e.g. their proteolytic activity contributes to the release and processing of factors such as fibroblast growth factor (FGF). MMPs can also inhibit apoptosis, as in the case of MMP-7, which can trigger an intracellular signaling pathway to promote cell survival $[2,4]$.

\section{Tumor migration, invasion, metastasis}

MMP-2 and MMP-9, which are capable of degrading type IV collagen and disrupting the integrity of the basement membrane have long been recognized to play a role in tumor invasion. Studies of MMP-9 and MMP-2-null mice provided further evidence of the role of these MMPs in metastasis [2]. Recently, it was found that MMP-10 plays a significant role in cervical tumor growth and progression through regulation of angiogenic and apoptotic pathways [38]. In addition, MMP-1 was shown to play a major role in tumor growth and angiogenesis. Its suppression in vivo reduced growth and angiogenesis of lung tumors [39]. Similar findings were reported for MT2-MMP associated with lung tumor progression and angiogenesis [40].

Valuable insight into these molecules was gained from direct visualization of MMP activity in vitro and in vivo as well as localization of their proteolytic activity during migration and invasion of tumor cells [41,42]. In that respect, several studies evaluated MMP-14 in tumor cells $[26,43,44]$, and found protease activity of MMP-14 to be localized at the polarized leading edge of the tumor cell [26] facilitating forward movement of the cell. However, controversy still exists as to extent of the role of MMPs in protease-dependent versus protease-independent amoeboid movement of tumor cells $[27,43,44]$. Using blocking antibodies against MMP-14 in a pancreatic cancer cell line, it was recently demonstrated that MMP-14 is an activator of several MMPs (MMP-2, MMP-9) and facilitates local ECM degradation and invasion [45].

\section{Angiogenesis and vasculogenesis}

Angiogenesis, the formation of new blood vessels within the tumor, is initiated when the tumor has reached a critical size. It involves MMP's degradation of ECM and non-ECM substrates and formation of new blood vessels from the pre-existing vascular network. In contrast, the de novo formation of blood vessels [14], which involves the development of endothelial cell networks by recruitment of circulating progenitors of the endothelial cells, is called vasculogenesis. During tumor progression the 'angiogenic switch' occurs when the balance between the proangiogenic and the antiangiogenic factors tilts towards a pro-angiogenic outcome. Some MMPs play an important role in the angiogenic process, MMP-9 is particularly known as a critical mediator of the angiogenic switch $[2,46]$. In addition Interleukin-32 (IL-32) has pro-angiogenic properties acting via regulation of MMP-9 and IL-8 and several other molecules [47]. We have previously shown correlation between increased angiogenesis and MMP-2 expression at the brain-tumor interface in CNS metastasis of lung carcinoma [32]. The gelatinases MMP-2 and MMP-9 are among the major MMPs affecting tumor angiogenesis [48].

\section{Pleiotropic activities of MMPs in tumor microenvironment}

Based on the observations that MMPs play an essential role in tumor cell proliferation, migration, invasion, metastasis and angiogenesis, it seemed very plausible that inhibiting MMPs at the tumor site would be a viable therapeutic target. The early transgenic mouse models overexpressing various MMPs supported the notion that MMPs contribute to tumor progression [49]. In addition, the observation that high levels of MMPs correlated with poor prognosis of cancer patients, paved the way for the clinical trials using inhibitors of MMPs. The outcomes of these trials were disappointing showing that indiscriminate targeting and broad spectrum inhibition of MMPs did not result in the anticipated inhibitory effect on the tumor growth. 
On the contrary, in some studies inhibition of MMPs or MMPinduced molecules resulted in promoting tumor growth [50,51]. These unexpected findings led to the extensive studies using new mouse models of MMP knock-outs in which the generation of gain or loss-of function revealed the highly complex and pleiotropic nature of MMPs and their function [52]. Currently available MMP knock-out mouse models only encompass 17 out of 23 murine MMP genes. Additional MMP knock-out mouse models are necessary in order to better understand MMPs functions in human malignancies. In addition, generation of double or even triple knock-out mouse models may be necessary to minimize existing functional redundancy or compensatory mechanisms between various members of MMP family $[6]$.

\section{Suppressive and Stimulatory Effects of MMPs on Tumor Growth and Microenvironment}

There are number of MMPs that can stimulate or suppress tumor growth, but some can exhibit both of these activities. In addition, remodeling of cell surface, basement membrane and ECM by MMPs, leads to the release of several membrane- or matrix-bound growth factors and cytokines. This includes for example positive and negative regulators of angiogenesis that impact tumor growth.

\section{Stimulatory activities of MMPs}

Several MMPs were shown to stimulate tumor growth, e.g., MMP-1. However, indirect stimulatory activities of MMPs on tumor progression are known as well. For example, one of the most studied positive regulators of angiogenesis released from ECM by MMP proteolysis is VEGF. In this regard, numerous studies have reported the effect of MMP-9 derived from inflammatory leukocytes such as macrophages and neutrophils [53] as well tumor cells [54] on VEGF release. Also, MMP-2 and MMP-14 were shown to be involved in mobilization and upregulation of VEGF [55,56]. In addition, MMP-3, 7 and 19 cleave matrix-bound isoforms of VEGF [57]. FGF-2, another molecule with stimulatory activity on angiogenesis is released from the ECM as result of proteolytic activity of MMPs [58,59]. Endothelial basement membrane-bound FGF-2 resides in ECM as an inactive form and needs to be proteolytically cleaved and released from ECM in order to be biologically active [60,61]. MMP-9 was shown to induce the release of FGF-2 [59]. In addition, new findings have shown that thyroid-hormone may be regulating adhesion, migration and MMP-9 activity in myeloma cells via integrin. This may lead to the development of new therapeutic targets for the treatment of myeloma by allowing a disruption of the thyroid-hormone-integrin-MMP-9 signaling cascade [62].

\section{Suppressive activities of MMPs}

Although many MMPs stimulate tumor growth, there are some MMPs that can suppress tumorigenesis. The generation of new genetically modified animal models demonstrated that several MMPs, such as MMP-8 and MMP-12 have inhibitory activities on tumor growth. MMP-8 plays a protective role in cancer because of its capability to regulate the inflammatory response. The expression of MMP-8 derived from neutrophils was shown to be elevated in nonmetastatic cell line and correlated with its protective effect on tumor cell invasion and metastasis [2,63,64]. MMP-12 overexpression in colon cancer cells was shown to be associated with increased survival [65]. In addition, it was reported that MMP-12 overexpression in myeloid lineage cells affected modulation of myelopoiesis and resulted in immune suppression. This study was done both in in vitro and in vivo using immature cells from MMP12-overexpressing bitransgenic mice showing immunosuppressive function of these immature cells on T-cell proliferation and function [66]. Similarly, it was shown in mice deficient for MMP inhibitor-TIMP-2, that there was an elevated MMP activation associated with an increase in myeloid-derived suppressor cells coexpressing VEGF [67]. Recently, tumor-suppressive functions of MMP-9 were shown in colitis-associated cancer [68] and in colorectal cancer [69].

In addition, inhibitors of angiogenesis are also released indirectly during ECM remodeling by MMPs [33]. These inhibitors include angiostatin, endostatin, and tumstatin [70]. The MMPs capable of contributing to the production of angiostatin include MMP-2,7,9, and 12 with MMP-12 being the most efficient inducer of angiostatin resulting in inhibition of angiogenesis [71,72]. Endostatin, another inhibitor of angiogenesis was reported to be produced by cleavage from collagen type XVIII of basement membrane by MMP-3, -7, -9, -12 and -20. Also some select MMPs, e.g., MMP-9 were implicated in production of tumstatin, another inhibitor of angiogenesis, from collagen type IV [71].

\section{MMPs and MMPs-induced molecules as targets for cancer therapy}

Clinical studies using inhibitors of MMPs failed to show desired, expected anti-tumor effect [50,51]. The original premise for targeting MMPs was an understanding that MMPs are primarily involved in degradation of ECM proteins that play a key role in metastasis and angiogenesis [73]. It is now known that several MMPs can play dual roles as tumor stimulators or inhibitors depending on the type of tissue and progression of the disease. There are several MMPs that have this dual role, e.g MMP-3, 9 and 11 [2, 6,74,75]. In addition, depending on the cellular source of the same MMP, e.g. MMP-12, could be pro-tumorigenic when derived from tumor cells. However, when derived from tumor-associated macrophages, MMP-12 has a protective effect leading to differentiation of tumor cells followed by better outcome of the disease [76].

A similar finding related to MMP-induced molecules such as VEGF involved in tumor angiogenesis and known to be sequestered in the ECM. Targeting and inhibition of the VEGF pathway in vivo in pancreatic carcinoma and glioblastoma mouse models resulted in worsening of the disease process by increasing tumor cell invasiveness and metastasis [77]. Similarly it was shown that deletion of VEGF in myeloid cells accelerated tumorigenesis [78]. Yet, another paradox was reported relating to MMP-9, which is known to be associated with the production of tumstatin, an inhibitor of angiogenesis. It is known that MMP-9 activity is associated either with promoting or decreasing angiogenesis.

The first anticancer broad-spectrum MMP inhibitors used in clinical trials were tested alone or in combination with standard chemotherapeutics in patients with advanced pancreatic, brain, lung prostate and gastrointestinal cancers. However, after Phase III clinical trials, failed to show efficacy, but often significant side effects, further clinical studies were conducted [73]. There is also a large body of literature covering various dietary antioxidants and cannabinoids on MMPs' role in cancer growth [79-81].

Some recently developed modalities of nanodelivery of therapeutics which target tumors more efficiently, resulted in tumor cell growth 
arrest, apoptosis, and prolonged survival in vivo. This was associated with reduction of VEGF secretion, reduction of blood vessel density and decreased MMP levels. An example of this methodology was the selective therapeutic targeting via nanodelivery of anaplastic lymphoma kinase (ALK)-specific siRNA for the treatment of neuroblastoma [82]. In another study investigators used nanoparticle based delivery of tetrandrine to lung cancer cells [83]. They showed that nanoparticle delivered tetrandrine inhibited migration and invasion of lung cancer cells more efficiently than free tetrandrine by down-regulating MMP-2 and MMP-9.

The implication of MMPs in cancer development and progression continue to be of great significance. Current research efforts are focusing on learning more about the mechanism of action of MMPs as well as the discovery of new, selective therapeutic targets for MMP activity. MMP inhibitors thus remain strong considerations for the development of anticancer therapies.

\section{References}

1. Gross J, Lapiere CM (1962) Collagenolytic activity in amphibian tissues: a tissue culture assay. Proc Natl Acad Sci U S A 48: 1014-1022.

2. Martin MD, Matrisian LM (2007) The other side of MMPs: protective roles in tumor progression. Cancer Metastasis Rev 26: 717-724.

3. Page-McCaw A, Ewald AJ, Werb Z (2007) Matrix metalloproteinases and the regulation of tissue remodelling. Nat Rev Mol Cell Biol 8: 221-233.

4. Rodríguez D, Morrison CJ, Overall CM (2010) Matrix metalloproteinases: what do they not do? New substrates and biological roles identified by murine models and proteomics. Biochim Biophys Acta 1803: 39-54.

5. Nissinen L, Kähäri VM (2014) Matrix metalloproteinases in inflammation. Biochim Biophys Acta 1840: 2571-2580.

6. Fanjul-Fernández M, Folgueras AR, Cabrera S, López-Otín C (2010) Matrix metalloproteinases: evolution, gene regulation and functional analysis in mouse models. Biochim Biophys Acta 1803: 3-19.

7. Klein T, Bischoff R (2011) Physiology and pathophysiology of matrix metalloproteases. Amino Acids 41: 271-290.

8. Rojiani MV, Wiranowska M, Rojiani AM (2011) Matrix Metalloproteinases and Their Inhibitors-Friend or Foe. In: Siemann D (ed.) Tumor Microenvironment. J. Wiley and Sons, Ltd., pp. 53-76.

9. Wiranowska M, Rojiani MV (2011) Extracellular Matrix Microenvironment in Glioma Progression. In: Ghosh A (ed.) GliomaExploring its Biology and Practical Relevance. InTech Open Access Publisher.

10. Wiranowska M, Rojiani MV (2013) Glioma extracellular matrix molecules as therapeutic targets. In: Wiranowska M, Vrionis FD (eds.) Gliomas: Symptoms, Diagnosis and Treatment Options. Nova Science Publishers, New York, pp. 263-286.

11. Hu F, a Dzaye OD, Hahn A, Yu Y, Scavetta RJ, et al. (2015) Gliomaderived versican promotes tumor expansion via glioma-associated microglial/macrophages Toll-like receptor 2 signaling. Neuro Oncol 17: 200-210.

12. Coussens LM, Raymond WW, Bergers G, Laig-Webster M, Behrendtsen O, et al. (1999) Inflammatory mast cells up-regulate angiogenesis during squamous epithelial carcinogenesis. Genes \& development 13: 1382-1397.

13. Deryugina EI, Quigley JP (2006) Matrix metalloproteinases and tumor metastasis. Cancer Metastasis Rev 25: 9-34.

14. Deryugina EI, Quigley JP (2010) Pleiotropic roles of matrix metalloproteinases in tumor angiogenesis: contrasting, overlapping and compensatory functions. Biochim Biophys Acta 1803: 103-120.

15. van Hinsbergh VW, Koolwijk P (2008) Endothelial sprouting and angiogenesis: matrix metalloproteinases in the lead. Cardiovasc Res 78: 203-212.
16. Taddei ML, Giannoni E, Comito G, Chiarugi P (2013) Microenvironment and tumor cell plasticity: an easy way out. Cancer Lett 341: 80-96.

17. Wang W, Bergh A, Damber JE (2005) Cyclooxygenase-2 expression correlates with local chronic inflammation and tumor neovascularization in human prostate cancer. Clin Cancer Res 11: 3250-3256.

18. Zarogoulidis P, Katsikogianni F, Tsiouda T, Sakkas A, Katsikogiannis N, et al. (2014) Interleukin-8 and interleukin-17 for cancer. Cancer Invest 32: 197-205.

19. Hua G, Haiping Z, Baorong H, Dingjun H (2013) Effect of ulinastatin on the expression of iNOS, MMP-2, and MMP-3 in degenerated nucleus pulposus cells of rabbits. Connect Tissue Res 54: 29-33.

20. McQuibban GA, Gong JH, Tam EM, McCulloch CA, Clark-Lewis I, et al. (2000) Inflammation dampened by gelatinase A cleavage of monocyte chemoattractant protein-3. Science 289: 1202-1206.

21. Wiranowska $M$, Naidu AK (1994) Interferon effect on glycosaminoglycans in mouse glioma in vitro. J Neurooncol 18: 9-17.

22. Wiranowska M, Tresser N, Saporta S (1998) The effect of interferon and anti-CD44 antibody on mouse glioma invasiveness in vitro. Anticancer Res 18: 3331-3338.

23. Yu Q, Stamenkovic I (1999) Localization of matrix metalloproteinase 9 to the cell surface provides a mechanism for CD44-mediated tumor invasion. Genes Dev 13: 35-48.

24. Egeblad M, Werb Z (2002) New functions for the matrix metalloproteinases in cancer progression. Nat Rev Cancer 2: 161-174.

25. Itoh Y, Seiki M (2006) MT1-MMP: a potent modifier of pericellular microenvironment. J Cell Physiol 206: 1-8.

26. Packard BZ, Artym VV, Komoriya A, Yamada KM (2009) Direct visualization of protease activity on cells migrating in three-dimensions. Matrix Biol 28: 3-10.

27. Sabeh F, Shimizu-Hirota R, Weiss SJ (2009) Protease-dependent versus independent cancer cell invasion programs: three-dimensional amoeboid movement revisited. J Cell Biol 185: 11-19.

28. Genís L, Gálvez BG, Gonzalo P, Arroyo AG (2006) MT1-MMP: universal or particular player in angiogenesis? Cancer Metastasis Rev 25: 77-86.

29. van Beem RT, Verloop RE, Kleijer M, Noort WA, Loof N, et al. (2009) Blood outgrowth endothelial cells from cord blood and peripheral blood: angiogenesis-related characteristics in vitro. J Thromb Haemost 7: 217-226.

30. Davis GE, Senger DR (2008) Extracellular matrix mediates a molecular balance between vascular morphogenesis and regression. Curr Opin Hematol 15: 197-203.

31. Oh J, Takahashi R, Kondo S, Mizoguchi A, Adachi E, et al. (2001) The membrane-anchored MMP inhibitor RECK is a key regulator of extracellular matrix integrity and angiogenesis. Cell 107: 789-800.

32. Rojiani MV, Alidina J, Esposito N, Rojiani AM (2010) Expression of MMP-2 correlates with increased angiogenesis in CNS metastasis of lung carcinoma. Int J Clin Exp Pathol 3: 775-781.

33. Kalluri R (2003) Basement membranes: structure, assembly and role in tumour angiogenesis. Nat Rev Cancer 3: 422-433.

34. Wiranowska M, Ladd S, Smith SR, Gottschall PE (2006) CD44 adhesion molecule and neuro-glial proteoglycan NG2 as invasive markers of glioma. Brain Cell Biol 35: 159-172.

35. Seiki M (2002) The cell surface: the stage for matrix metalloproteinase regulation of migration. Curr Opin Cell Biol 14: 624-632.

36. Leppert D, Lindberg RL, Kappos L, Leib SL (2001) Matrix metalloproteinases: multifunctional effectors of inflammation in multiple sclerosis and bacterial meningitis. Brain Res Brain Res Rev 36: 249-257.

37. Wiranowska M, Plaas A (2008) Cytokines and Extracellular Matrix Remodeling in the Central Nervous System. NeuroImmune Biology 6: 167-197.

38. Zhang G, Miyake M, Lawton A, Goodison S, Rosser CJ (2014) Matrix metalloproteinase-10 promotes tumor progression through regulation of angiogenic and apoptotic pathways in cervical tumors. BMC Cancer 14: 310 . 
39. Foley CJ, Fanjul-Fernández M, Bohm A, Nguyen N, Agarwal A, et al. (2014) Matrix metalloprotease 1a deficiency suppresses tumor growth and angiogenesis. Oncogene 33: 2264-2272.

40. Chen L, Zhou Q, Xu B, Liu J, Shi L, et al. (2014) MT2-MMP expression associates with tumor progression and angiogenesis in human lung cancer. Int J Clin Exp Pathol 7: 3469-3477.

41. Sloane BF, Sameni M, Podgorski I, Cavallo-Medved D, Moin K (2006) Functional imaging of tumor proteolysis. Annu Rev Pharmacol Toxicol 46: 301-315.

42. Hobson JP, Liu S, Rønø B, Leppla SH, Bugge TH (2006) Imaging specific cell-surface proteolytic activity in single living cells. Nat Methods 3: 259-261.

43. Wolf K, Mazo I, Leung H, Engelke K, von Andrian UH, et al. (2003) Compensation mechanism in tumor cell migration: mesenchymalamoeboid transition after blocking of pericellular proteolysis. J Cell Biol 160: 267-277.

44. Wolf K, Wu YI, Liu Y, Geiger J, Tam E, et al. (2007) Multi-step pericellular proteolysis controls the transition from individual to collective cancer cell invasion. Nat Cell Biol 9: 893-904.

45. Haage A, Nam DH, Ge X, Schneider IC (2014) Matrix metalloproteinase-14 is a mechanically regulated activator of secreted MMPs and invasion. Biochem Biophys Res Commun 450: 213-218.

46. Baeriswyl V, Christofori G (2009) The angiogenic switch in carcinogenesis. Semin Cancer Biol 19: 329-337.

47. Nold-Petry CA, Rudloff I, Baumer Y, Ruvo M, Marasco D, et al. (2014) IL-32 promotes angiogenesis. J Immunol 192: 589-602.

48. Kessenbrock K, Plaks V, Werb Z (2010) Matrix metalloproteinases: regulators of the tumor microenvironment. Cell 141: 52-67.

49. Ha HY, Moon HB, Nam MS, Lee JW, Ryoo ZY, et al. (2001) Overexpression of membrane-type matrix metalloproteinase-1 gene induces mammary gland abnormalities and adenocarcinoma in transgenic mice. Cancer Res 61: 984-990.

50. Coussens LM, Fingleton B, Matrisian LM (2002) Matrix metalloproteinase inhibitors and cancer: trials and tribulations. Science 295: 2387-2392.

51. Fingleton B (2008) MMP Inhibitor Clinical Trials-The Past, Present, and Future. The Cancer Degradome 759-785.

52. Krüger A (2009) Functional genetic mouse models: promising tools for investigation of the proteolytic internet. Biol Chem 390: 91-97.

53. Bergers G, Brekken R, McMahon G, Vu TH, Itoh T, et al. (2000) Matrix metalloproteinase- 9 triggers the angiogenic switch during carcinogenesis. Nat Cell Biol 2: 737-744.

54. Belotti D, Paganoni P, Manenti L, Garofalo A, Marchini S, et al. (2003) Matrix metalloproteinases (MMP9 and MMP2) induce the release of vascular endothelial growth factor (VEGF) by ovarian carcinoma cells: implications for ascites formation. Cancer Res 63: 5224-5229.

55. Dean RA, Overall CM (2007) Proteomics discovery of metalloproteinase substrates in the cellular context by iTRAQ labeling reveals a diverse MMP-2 substrate degradome. Mol Cell Proteomics 6: 611-623.

56. Deryugina EI, Soroceanu L, Strongin AY (2002) Up-regulation of vascular endothelial growth factor by membrane-type 1 matrix metalloproteinase stimulates human glioma xenograft growth and angiogenesis. Cancer Res 62: 580-588.

57. Lee S, Jilani SM, Nikolova GV, Carpizo D, Iruela-Arispe ML (2005) Processing of VEGF-A by matrix metalloproteinases regulates bioavailability and vascular patterning in tumors. J Cell Biol 169: 681-691.

58. Presta M, Dell'Era P, Mitola S, Moroni E, Ronca R, et al. (2005) Fibroblast growth factor/fibroblast growth factor receptor system in angiogenesis. Cytokine Growth Factor Rev 16: 159-178.

59. Ardi VC, Van den Steen PE, Opdenakker G, Schweighofer B, Deryugina EI, et al. (2009) Neutrophil MMP-9 proenzyme, unencumbered by TIMP-1, undergoes efficient activation in vivo and catalytically induces angiogenesis via a basic fibroblast growth factor (FGF-2)/FGFR-2 pathway. J Biol Chem 284: 25854-25866.
60. Iozzo RV, San Antonio JD (2001) Heparan sulfate proteoglycans: heavy hitters in the angiogenesis arena. J Clin Invest 108: 349-355.

61. Sanderson RD, Yang Y, Kelly T, MacLeod V, Dai Y, et al. (2005) Enzymatic remodeling of heparan sulfate proteoglycans within the tumor microenvironment: growth regulation and the prospect of new cancer therapies. J Cell Biochem 96: 897-905.

62. Cohen K, Flint N, Shalev S, Erez D, Baharal T, et al. (2014) Thyroid hormone regulates adhesion, migration and matrix metalloproteinase 9 activity via $\alpha v \beta 3$ integrin in myeloma cells. Oncotarget 5: 6312-6322.

63. López-Otín C, Matrisian LM (2007) Emerging roles of proteases in tumour suppression. Nat Rev Cancer 7: 800-808.

64. Gutiérrez-Fernández A, Fueyo A, Folgueras AR, Garabaya C, Pennington CJ, et al. (2008) Matrix metalloproteinase- 8 functions as a metastasis suppressor through modulation of tumor cell adhesion and invasion. Cancer Res 68: 2755-2763.

65. Yang W, Arii S, Gorrin-Rivas MJ, Mori A, Onodera H, et al. (2001) Human macrophage metalloelastase gene expression in colorectal carcinoma and its clinicopathologic significance. Cancer 91: 1277-1283.

66. Qu P, Yan C, Du H (2011) Matrix metalloproteinase 12 overexpression in myeloid lineage cells plays a key role in modulating myelopoiesis, immune suppression, and lung tumorigenesis. Blood 117: 4476-4489.

67. Guedez L, Jensen-Taubman S, Bourboulia D, Kwityn CJ, Wei B, et al. (2012) TIMP-2 targets tumor-associated myeloid suppressor cells with effects in cancer immune dysfunction and angiogenesis. J Immunother 35: 502-512.

68. Garg P, Sarma D, Jeppsson S, Patel NR, Gewirtz AT, et al. (2010) Matrix metalloproteinase- 9 functions as a tumor suppressor in colitis-associated cancer. Cancer Res 70: 792-801.

69. Bendardaf R, Buhmeida A, Hilska M, Laato M, Syrjänen S, et al. (2010) MMP-9 (gelatinase B) expression is associated with disease-free survival and disease-specific survival in colorectal cancer patients. Cancer Invest 28: 38-43.

70. Folkman J (2004) Endogenous angiogenesis inhibitors. APMIS 112: 496-507.

71. Nyberg P, Xie L, Kalluri R (2005) Endogenous inhibitors of angiogenesis. Cancer Res 65: 3967-3979.

72. Gorrin-Rivas MJ, Arii S, Furutani M, Mizumoto M, Mori A, et al. (2000) Mouse macrophage metalloelastase gene transfer into a murine melanoma suppresses primary tumor growth by halting angiogenesis. Clin Cancer Res 6: 1647-1654.

73. Dufour A, Overall CM (2013) Missing the target: matrix metalloproteinase antitargets in inflammation and cancer. Trends Pharmacol Sci 34: 233-242.

74. Andarawewa KL, Boulay A, Masson R, Mathelin C, Stoll I, et al. (2003) Dual stromelysin-3 function during natural mouse mammary tumor virus-ras tumor progression. Cancer Res 63: 5844-5849.

75. Jost M, Folgueras AR, Frérart F, Pendas AM, Blacher S, et al. (2006) Earlier onset of tumoral angiogenesis in matrix metalloproteinase-19deficient mice. Cancer Res 66: 5234-5241.

76. Kerkelä E, Ala-aho R, Klemi P, Grénman S, Shapiro SD, et al. (2002) Metalloelastase (MMP-12) expression by tumour cells in squamous cell carcinoma of the vulva correlates with invasiveness, while that by macrophages predicts better outcome. J Pathol 198: 258-269.

77. Pàez-Ribes M, Allen E, Hudock J, Takeda T, Okuyama H, et al. (2009) Antiangiogenic therapy elicits malignant progression of tumors to increased local invasion and distant metastasis. Cancer Cell 15: 220-231.

78. Stockmann C, Doedens A, Weidemann A, Zhang N, Takeda N, et al. (2008) Deletion of vascular endothelial growth factor in myeloid cells accelerates tumorigenesis. Nature 456: 814-818.

79. Kim A, Im M, Ma JY (2014) Anisi stellati fructus extract attenuates the in vitro and in vivo metastatic and angiogenic potential of malignant cancer cells by downregulating proteolytic activity and pro-angiogenic factors. Int J Oncol 45: 1937-48. 
Citation: Wiranowska M, Rojiani AM, Rojiani MV (2015) Matrix Metalloproteinases-Modulating the Tumor Microenvironment. J Carcinog Mutagen 6: 225. doi:10.4172/2157-2518.1000225

Page 7 of 7

80. Verma S, Kesh K, Ganguly N, Jana S, Swarnakar S (2014) Matrix metalloproteinases and gastrointestinal cancers: Impacts of dietary antioxidants. World J Biol Chem 5: 355-376.

81. Ramer R, Fischer S, Haustein M, Manda K, Hinz B (2014) Cannabinoids inhibit angiogenic capacities of endothelial cells via release of tissue inhibitor of matrix metalloproteinases-1 from lung cancer cells. Biochemical pharmacology 91: 202-16.

82. Di Paolo D, Ambrogio C, Pastorino F, Brignole C, Martinengo C, et al. (2011) Selective therapeutic targeting of the anaplastic lymphoma kinase with liposomal siRNA induces apoptosis and inhibits angiogenesis in neuroblastoma. Mol Ther 19: 2201-12.

83. Xu H, Hou Z, Zhang H, Kong H, Li X, et al. (2014) An efficient Trojan delivery of tetrandrine by poly (N-vinylpyrrolidone)-block-poly (epsiloncaprolactone) (PVP-b-PCL) nanoparticles shows enhanced apoptotic induction of lung cancer cells and inhibition of its migration and invasion. Int J Nanomedicine 9: 231-242. 